\title{
Current role of orthodontists in treating temporo-mandibular disorders
}

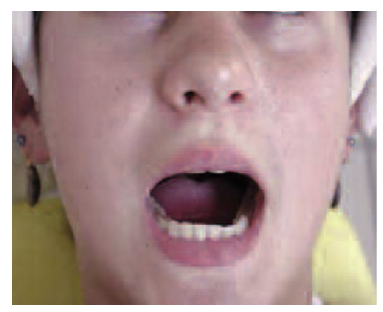

\author{
Wacyl MESNAY
}

\section{ABSTRACT}

At one time or another all orthodontists have to deal with a patient in their daily practice who sufferers from a temporo-mandibular disorder. Usually not well trained in this area they avoid the problem by referring the patient to an "occlusodontist" even though the majority of these TMD problems can be resolved by simple non-invasive techniques that any dentist can readily perform.

In this article I describe the therapeutic sequence of events. When pain is present, practitioners devote the initial appointment to establishing a diagnosis of "painful disorder." At the same time they must explain to their patients what the different psychosocial components of the TMD are. While the clinical examination practitioners conduct next is simple and speedily completed, its correct execution requires a certain apprenticeship. The result of properly concluded procedures is a precise diagnosis of the functional TMD problem.

Then I review the wide range of therapeutic possibilities that are currently available, which are comparable to those employed in medical rheumatology.

Finally, I present the treatment of a patient with TMD to illustrate the clinical application of this up-to-date approach.

\section{KEY WORDS}

TMJ,

Occlusion,

Temporo-mandibular disorder, TMD,

Painful disorder,

Clinical examination,

Diagnosis,

Clinical case. 


\section{1 - INTRODUCTION}

Orthodontists frequently refer patients with the signs and symptoms of temporo-mandibular disorders, TMD, to other specialists. These complaints are often associated with other general musculo-skeletal problems, which makes what these patients constitute a medically identifiable group. On first discerning their symptoms about $50 \%$ of patients in this category first consult a medical general practitioner. Next they seek the help of a general dentist or, if they have had previous orthodontic treatment, often go to an orthodontist. Others are referred to orthodontists by medical or dental general practitioners. So it is important for orthodontists to know how to make a proper diagnosis of TMD and to be able to propose an initial treatment for it, which, in most cases, will be all that is needed.

The designation TMD, temporomandibular disorder, which was adopted by the 1996 consensus conference ${ }^{23}$, encompasses an ensemble of signs and symptoms that dentists, both generalists and specialists, must deal with wherever they practice in their own offices or in clinical or hospital settings.

\section{2 - EPIDEMIOLOGY}

Temporo-mandibular problems are a frequently occurring disorders with 45 to $70 \%$ of the general population showing some signs of $i^{25}, 30 \%$ being aware of its presence, but only 3 to $12 \%$ seeking treatment for it.
The principal signs and symptoms of TMD originate in the functioning of various muscular and components of the temporo-mandibular joint of the masticatory system. Pain and articular sounds often appear when patients open their mouths or during mastication. But the symptoms may also derive from, or accompany a loss of function such as holding a long sound, singing, or just mouth opening.

Other symptoms can be present, such as joint pains, headaches, or neck pains. Some patients experience occlusal discomfort, often upon awakening.

With these patients, dentists should focus especially on pain, particularly if it is of more than six months duration and not related to any specific masticatory activity. In fact the latest research in this area indicated this disorder is more complex than was previously thought. Psychosocial factors, physiological activity related to stress, and neuronal memory can influence and sustain the sensation of pain.

These prospective patients are primarily women (2 to 18\%) with males far behind in number $(0$ to $10 \%)^{11,30}$. According to Drangsholt and LaResche ${ }^{8}$, TMD problems rarely afflict children, with their prevalence 
increasing with adolescents, and peaking in 18 to 45 year old adults. As senescence approaches muscular problems tend to diminish and TMJ difficulties tend to stabilize. Different authors $^{15,31}$ have reported a range of variation in TMD between the sexes ranging from 1 man for every 2 women to 1 man for every 10 women. In France, epidemiological studies show that TMD is rare. The study undertaken by Unger and his collaborators for the French National Health Institute in 1989 on a population of 55, 727 people, 25, 969 male and 29,

\section{3 - REMINDERS AND DEFINITIONS}

\section{3- 1 - Temporo-mandibular troubles}

The designation temporo-mandibular-disorder, TMD, encompasses an ensemble of muscular, temporo-mandibular-joint, and skeletal signs and symptoms that affect the hard and soft tissues of the masticatory system. They are characterized by a variety of elements that occur independently or in conjunction:

- pain in the pre-auricular, auricular, jugal, and, or, temporal regions;

- a limitation of the amplitude of mandibular movements;

- and, to a widely varying extent, noises in the temporo-mandibularjoint as it functions

TMD have not only an impact on routine activities of a patient's daily life such as mastication and swallowing as well as phonation and facial expressions. But when pain is severe
758 female, used a self assessment questionnaire of 200 health related items. The detection of TMD was based on four questions whose validity had previously been tested (Unger F. et al., 1989 cited in Mesnay W. 1998) ${ }^{19}$ : Perception of pain (TMJ pain (TMJ pain the pre-auricular area and pain at mouth opening) and expression of dysfunction (crackling noise on opening and deviation on opening). The results of this investigation show that $10.8 \%$ of men and $15.4 \%$ of women in the sample showed signs of temporo-mandibular disorders.

it may impede patients' functioning in their family lives, their professional sphere, and in other social activities $^{24}$.

In this domain, as in all of medicine, signs refer to the manifestations observed by the practitioner, while symptoms are the subjective clinical manifestations as perceived and reported by patients.

\section{3 - 2 - Pain and pain problems}

\section{- Pain}

The International Association for the Study of Pain has defined it as "an unpleasant sensory and emotional experience associated with actual or potential tissue damage, or described in terms of such damage" ${ }^{\prime 21}$.

Muscular problems are usually the chief complaint that impels patients to seek a consultation. However, our 
understanding of the mechanisms of muscular pain are today still incomplete $^{20}$, with the simplistic explanations of "fatigue," "trauma," or "spasm," falling short of representing the reality of the phenomenon in most cases ${ }^{17,18}$.

The modern method of dealing with it consists of assessing the general status of the patient's central nervous system during the sensorial activation stimulated by the muscle. The modifications of pain perception caused by the vegetative hyperactivity generated by various types of stress are capable of increasing the perception of pain as well as contributing to the transformation of that pain perception into a permanent condition. In other words, emotional conditions related to stress induce a kind of vegetative hyperactivity that causes both bruxism and a painful muscular hypersensitivity. As this phenomenon persists the pain becomes chronic ${ }^{14,26}$.

This pain can be classified into two major categories:

- acute: derived from an excess of unpleasant stimulation over periods up to six months in length, associated with transient life problems. Acute pain plays the role of an alarm signal most frequently triggered by a lesion;

- chronic: pain is designated as chronic if it persists more than six months. It can be continuous or recurrent and usually is associated with a specific pathological entity. Its intensity depends on the type of stimulus that caused it and also on the patient's subjective perception of it. It can be accentuated by fatigue or stress, in which case it can be classified as a pain disorder.

\section{- Pain disorder}

The Diagnostic and Statistical Manual of Mental Disorders defines pain disorder as a syndrome that is present when physical pain is a patient's chief complaint.

Practitioners are justified in making a diagnosis of pain disorder when they recognize these criteria ${ }^{2}$.

- Pain in one or more anatomical sites is the predominant focus of the clinical presentation and is of sufficient severity to warrant clinical attention.

- The pain causes clinically significant distress or impairment in social, occupational, or other important areas of functioning.

- Psychological factors are judged to have an important role in the onset, severity, exacerbation, or maintenance of the pain.

- The symptom or deficit is not intentionally produced or feigned

- The pain is not better accounted for by a psychiatric problem, more specifically mood, anxiety, or psychotic disorder and does not meet criteria for dyspareunia.

The Diagnostic and Statistical Manual of Mental Disorders specifies a diagnosis of pain disorder can be made when "psychological factors are judged to have the major role in the onset, severity, exacerbation, or maintenance of the pain. (If a general medical condition is present, it does 
not have a major role in the onset, severity, exacerbation, or maintenance of the pain.)" It adds that practitioners should not whether the conditions is Acute (duration of less than 6 months) or Chronic (duration of 6 months or longer).

Practitioners should refer patients presenting with chronic pain disorder

\section{4 - ETIOLOGY}

Cases of TMD consist of an ensemble of problems whose etiology is often presented as multi-factorial.

The articular cases are attributed to an overloading of the TMJ, possibly related to a violent shock to the jaw $^{4-28}$. Other cases may result from stretching of ligaments in mastication, yawning, or forced opening ${ }^{13}$.

But most often the etiology stems from repetitive micro-traumas delivered during episodes of bruxism or tooth clenching. Structural alterations are revealed secondarily by TMJ sounds that vary in intensity.

Even though patients profer muscular pain as their principal complaint, practitioners must take their psychosocial environment into account because oral muscular problems originate from the same factors that cause musculo-skeletal troubles, like neck aches and back pain, throughout the body,29. In most cases, to facilities that specialize in pain management. But for patients with acute or moderate intensity pain disorder, practitioners should explain the various dimensions of their symptoms. The prognosis is favorable when the stress factors are clearly identifiable or specific.

emotional disturbances play an important role $e^{3,6}$.

The intensity of pain fluctuates in these problems. When psychological factors are the chief etiological component, the pain appears to sufferers to constitute a crisis, without any relationship to function ${ }^{5-22}$.

So examiners must look for the underlying stress, anxiety, or state of depression.

For years many dentists have been convinced that occlusal discrepancies were the principal triggering factor for TMD but recent studies have concluded that they are only a secondary factorr ${ }^{16-27}$.

But bruxism, an activity not under conscious control, often rhythmic when it occurs during sleep, or static in the form of clenching during waking hours, is a para-function that is still frequently declared to be at the origin of muscular pain.

\section{5 - CLASSIFICATION OF TEMPORO-MANDIBULAR DISORDERS}

The nosography we present here is based on the one that the Ameri- can Academy of Orofacial Pain proposed in $1996^{26}$, which itself was 
based on the work of Dworkin and LeResche published in in 1992 and revised in $2004^{9,10}$, with only the most frequently encountered entities retained (cf. tables I and II).

\section{6 - THE CONSULTATION}

Practitioners use initial TMD consultation visitsts to accomplish several objectives. First, after performing a preliminary examination and listening to the patients' chief complaints, examiners inform them about the nature of the temporo-mandibular disorders that are troubling them. Then after completing a thorough examination and a careful intake interview, prepare a diagnosis.

In a second visit, dentists present patients with a therapeutic solution to their pain or handicap to be achieved with medication, an orthopedic device, and, eventually, by advice and recommendations that will help them manage their oral behavior themselves and thus prevent relapse.

\section{The initial interview}

The initial interview is the most important element of the first consultation. The examiner uses it not only as the first step in making a diagnosis but also as an essential and substantial element in treatment by its own therapeutic effect:

- it encourages patients to undertake a cognitive restructuration of their ailment;

- it helps patients to discern the elements of stress that have contributed to provoking the TMD and, by recognizing them, diminish the emotional component of the pain.

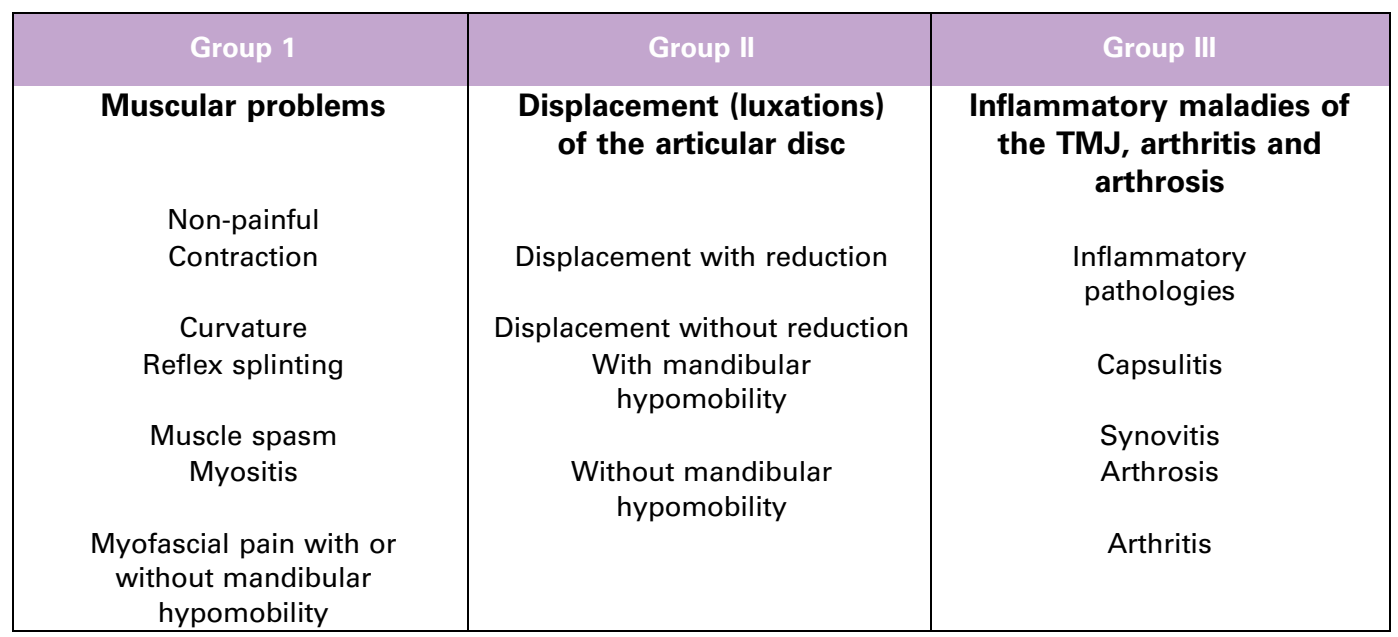

Table I

Nosography of temporo-mandibular disorders. 


\begin{tabular}{|c|c|c|c|c|c|c|}
\hline & Definition & Pain & Movements & $\begin{array}{l}\text { Palpation and } \\
\text { tests }\end{array}$ & Articular sounds & Others \\
\hline \multicolumn{7}{|c|}{ Muscular problems } \\
\hline Splint Reflex & Muscular rigidity & $\begin{array}{l}\text { Acute on } \\
\text { movement }\end{array}$ & $\begin{array}{l}\text { Limited } \\
\text { amplitude }\end{array}$ & $\begin{array}{l}\text { Muscular rigidity, } \\
\text { sensitivity }\end{array}$ & No & $\begin{array}{l}\text { Articular inflammation } \\
\text { Pericoronitis (trismus) }\end{array}$ \\
\hline Myospasm & Sudden contraction & Acute & $\begin{array}{l}\text { Limited } \\
\text { amplitude }\end{array}$ & $\begin{array}{l}\text { Muscular rigidity, } \\
\text { pain }\end{array}$ & No & $\begin{array}{l}\text { Fasiculation (contraction } \\
\text { of the whole of the } \\
\text { muscle) }\end{array}$ \\
\hline $\begin{array}{l}\text { Myofascial pain } \\
\text { Fibromyalgia }\end{array}$ & $\begin{array}{l}\text { Pain in muscles and } \\
\text { their fascias }\end{array}$ & $\begin{array}{l}\text { Many local sites } \\
\text { Dull, continuous } \\
\text { in tense muscle }\end{array}$ & $\begin{array}{l}\text { Sometimes } \\
\text { limited amplitude }\end{array}$ & $\begin{array}{l}\text { Pain in trigger } \\
\text { zones }\end{array}$ & No & $\begin{array}{l}\text { Not related to function, } \\
\text { related to anxiety and } \\
\text { depression } \\
\text { No etiological treatment }\end{array}$ \\
\hline
\end{tabular}

\section{Problems of the TMJ and its ligaments}

\begin{tabular}{|c|c|}
\hline Hypermobility & $\begin{array}{l}\text { Displacement of the } \\
\text { mandibular condyle beyond } \\
\text { the articular eminence of the } \\
\text { temporal bone }\end{array}$ \\
\hline Condyle luxation & $\begin{array}{l}\text { Luxation of the mandibular } \\
\text { condyle beyond the } \\
\text { eminence of the } \\
\text { temporal bone }\end{array}$ \\
\hline
\end{tabular}

\section{Problems of the TMJ and its ligaments}

\begin{tabular}{|c|c|c|c|c|c|c|}
\hline Discal subluxation & $\begin{array}{l}\text { The disc is deformed and } \\
\text { seems to be "displaced" } \\
\text { ahead of the condyle }\end{array}$ & No & $\begin{array}{l}\text { Unchanged amplitude, } \\
\text { but deviation in } \\
\text { opening and closing }\end{array}$ & $\begin{array}{l}\text { Test of positive } \\
\text { translation }\end{array}$ & $\begin{array}{l}\text { Characteristic } \\
\text { clicking on } \\
\text { opening, then in } \\
\text { closing (reciprocal } \\
\text { clicking) }\end{array}$ & $\begin{array}{l}\text { If TMJ pain exists it is a } \\
\text { case of capsulitis }\end{array}$ \\
\hline Disacal luxation & $\begin{array}{l}\text { Disc displaced ahead of } \\
\text { condyle during translation. } \\
\text { Disc is not spontaneously } \\
\text { recaptured during } \\
\text { translations }\end{array}$ & $\begin{array}{l}\text { Acute at initial } \\
\text { phase, disappears } \\
\text { with time }\end{array}$ & $\begin{array}{l}\text { Considerable } \\
\text { limitation, deviation } \\
\text { on opening toward } \\
\text { the injured side, } \\
\text { improves with time }\end{array}$ & $\begin{array}{l}\text { TMJ pain on pal- } \\
\text { pation and com- } \\
\text { pression that } \\
\text { diminishes on } \\
\text { translation }\end{array}$ & No & $\begin{array}{l}\text { Functional recuperation } \\
\text { over time }\end{array}$ \\
\hline \multicolumn{7}{|c|}{ TMJ problems of inflammation, arthritis and arthrosis } \\
\hline Capsulitis & $\begin{array}{l}\text { Inflammation of the articular } \\
\text { capsule }\end{array}$ & $\begin{array}{l}\text { Absent at rest, } \\
\text { feels like a needle } \\
\text { stick in function }\end{array}$ & $\begin{array}{l}\text { Amplitude sometimes } \\
\text { limited by muscular } \\
\text { splinting reflex }\end{array}$ & $\begin{array}{l}\text { Pain in joint } \\
\text { aggravated by } \\
\text { compression tests }\end{array}$ & No & $\begin{array}{l}\text { Sometimes associated } \\
\text { with trauma }\end{array}$ \\
\hline Arthrosis & $\begin{array}{l}\text { Non-inflammatory } \\
\text { degenerative condition. } \\
\text { Changes of shape of } \\
\text { articular osseous surfaces }\end{array}$ & $\begin{array}{l}\text { Rare, sometimes } \\
\text { dull and dee }\end{array}$ & $\begin{array}{l}\text { Amplitude varies. } \\
\text { Sometimes deviation } \\
\text { toward affected side }\end{array}$ & Negative & Crepitations & $\begin{array}{l}\text { Presence of osteophytes } \\
\text { visible on radiographs }\end{array}$ \\
\hline Arthritis & $\begin{array}{l}\text { Acute phase of inflammation } \\
\text { and degeneration }\end{array}$ & $\begin{array}{l}\text { Related to a } \\
\text { phase of arthrosis }\end{array}$ & $\begin{array}{l}\text { Irregular movements, } \\
\text { limited opening, } \\
\text { deviation toward } \\
\text { afected side }\end{array}$ & Sensitive & Crepitations & $\begin{array}{l}\text { Presence of } \\
\text { inflammatory } \\
\text { geoodes }\end{array}$ \\
\hline
\end{tabular}

\section{Table II}

Principal signs of tempero-mandibular disorders.
Amlitude of opening increased

Blocking on opening

On external palpation, dentist can sense the mandibular condyle

$\begin{aligned} & \text { Condyle passing } \\ & \text { the eminence }\end{aligned}$
$\begin{aligned} & \text { On external pal- } \\ & \text { pation, dentist } \\ & \text { can sense the } \\ & \text { mandibular con- } \\ & \text { dyle }\end{aligned}$

Clicking at end of opening

No

moment of

displacement

infection, or othe

Appears on movement

Articular inflammation

nitis (trismus)

of the whole of the

muscle)

No etiological treatment 
The examiner attempts to uncover these emotional elements wth questions of this type:

- how long has this pain been bothering you:

- under what circumstances does it appear?

- what aggravates and what tends to relive this pain? Behavioral difficulties like addiction may accompany the TMD and it may also be associated with family members who may show no concern or, on the contrary, be overly solicitous;
- if the pain is of long duration, how has it evolved over time? And in what life stages has it been most pronounced?

- tell me something about how well you sleep, how good your appetite is. Do you have problems with your tonsils? Do you often get nauseas? Do you have dizzy spells, vertigo, constipation? Answers to these questions may provide valuable information about possible anxiety disorders or depression;

- did you have a serious episode of stress during this past year?

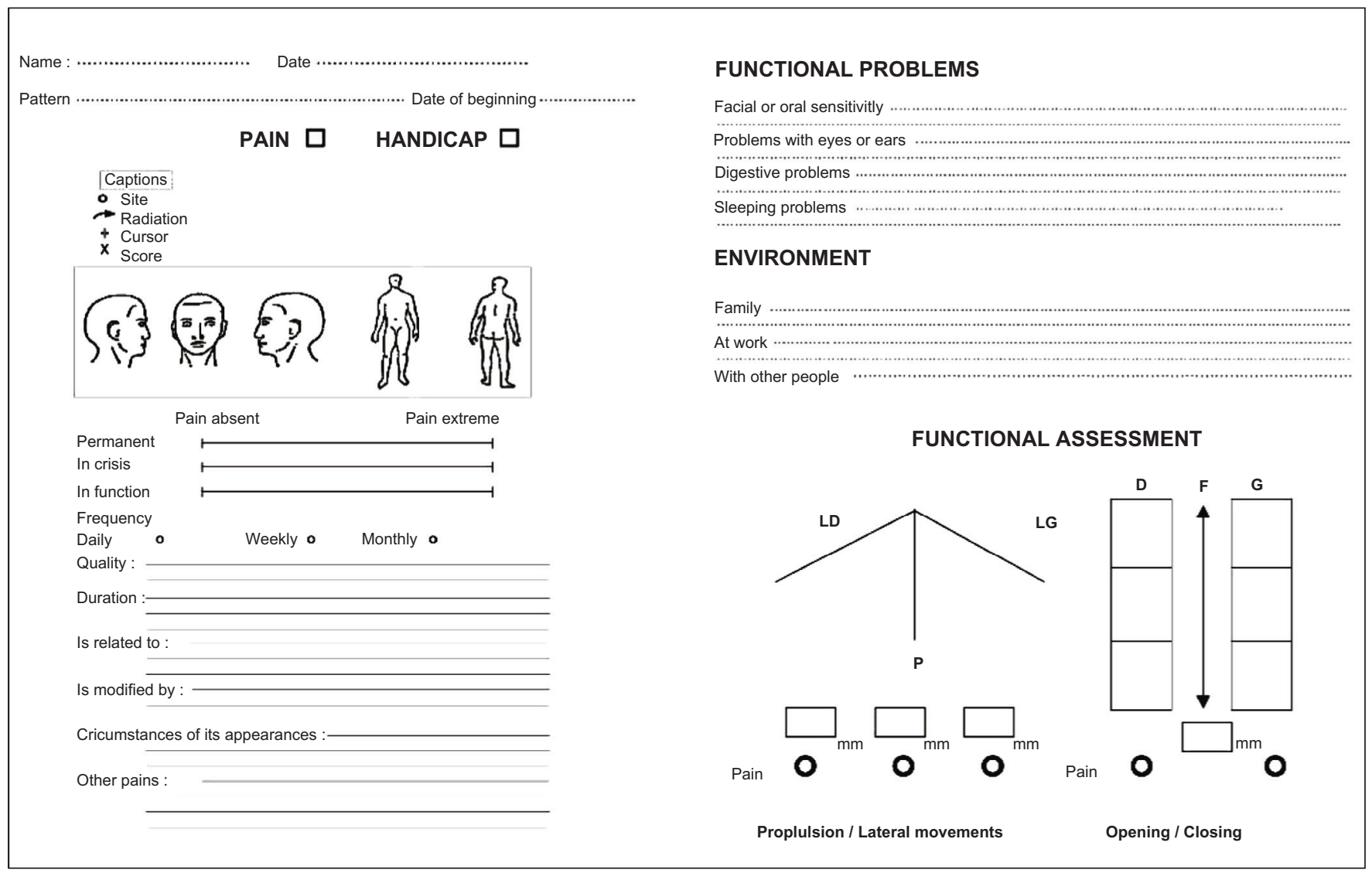

Figure 1

Clinical record of the initial intervieew. Pain is evaluated on a visual analogy scale. Functional troubles and environmental problems are reported in relation the the patient's stress level. 
- do you have conflicts with one or more family members or close friends?

- do you think you are living through a particularly difficult episode at this moment?

\section{7 - THE CLINICAL EXAMINATION}

The examiner uses the clinical examination to establish a precise, positive diagnosis of the muscular or joint disorder.

\section{7 - 1 - The functional assessment}

The examiner observes and measures the amplitude of active and practitioner-guided passive movements of the mandible in opening, closing, and in lateral and propulsive excursion (fig. 2 and 3 ) and records findings in the clinical record shown in figure 1 where all deviations and limitations are represented together

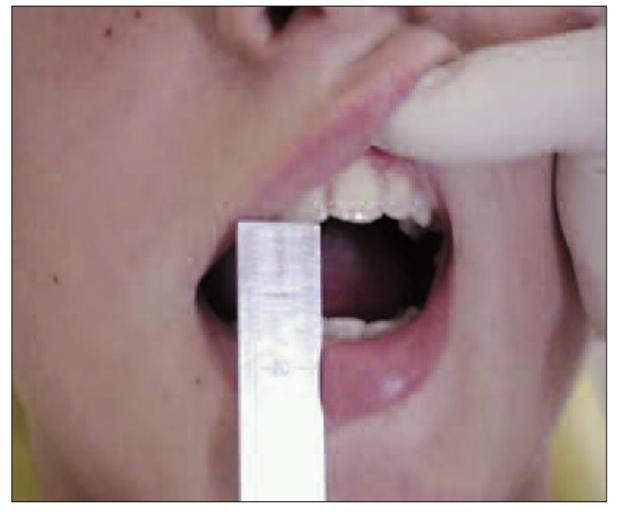

Figures $2 a$ and $2 b$

Measuring the amplitude and deviation of mandibular movement.

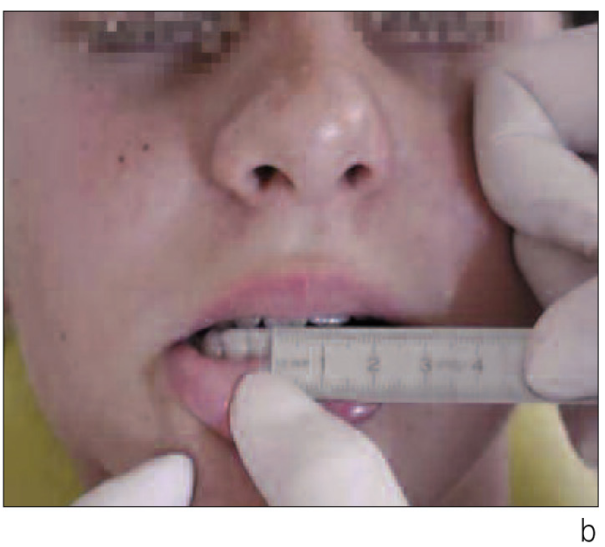

- do you have any problems concentrating or in completing work?

- do you feel anxious or depressed right now?

with the trajectories of opening and closing. The presence of sensitivity or pain at point in movement is also recorded in the appropriate space as are articular sounds of clicking and crepitation that occur in opening or closing.

\section{7 - 2 - Examination of the TMJ}

\section{- Ascultation (fig. 4)}

For years, examiners have used a stethoscope to listen for TMJ sounds but clinicaal experience and recent evaluation studies have indicated that the reliability of an examiner's digital perceptions is acceptably high.

b 

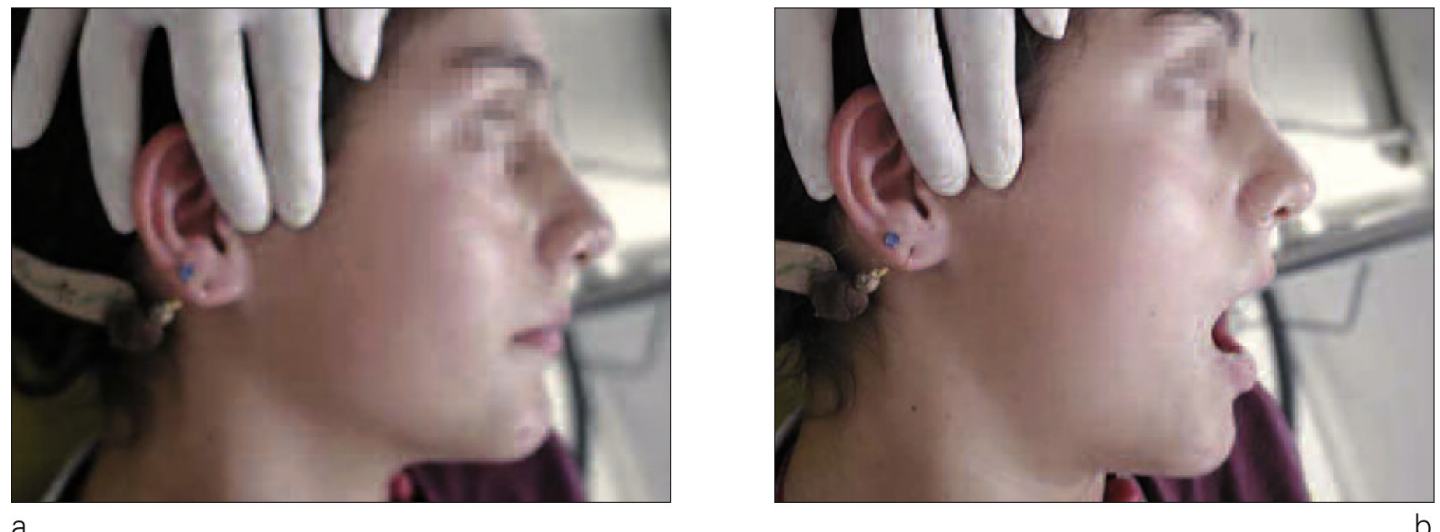

Figures $3 a$ and $3 b$

Digital palpation of the TMJ in movement, profile views.
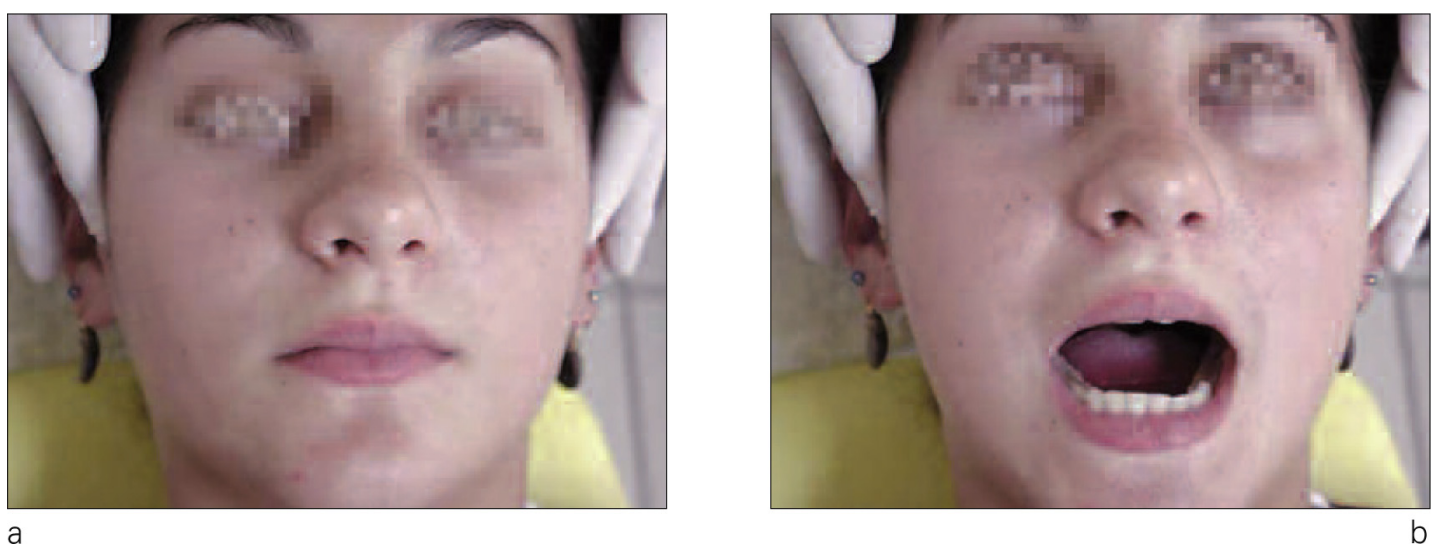

a

Figures $4 a$ and $4 b$

Digital TMJ palpation, full face views.

To carry out a digital palpation of the TMJ for articular sounds practitioners place their index and middle fingers on the articular line around patients' ears as they open and close and put their mandibles through excursive movements, recording all clicking and crispation.

\section{- Palpation of external and posterior poles (fig. 5)}

Examiners place their index fingers on the articular interline and ask patients to execute mandibular movements. Then they move that finger to the anterior portion of the exterior ear for retro-condylar palpation.

These zones may be tender when inflammation is present in the TMD.

\section{- The mandible in guided movement}

Examiners place themselves behind patients and ask them to move their jaws to the light or left while they put their fingers under patients' 


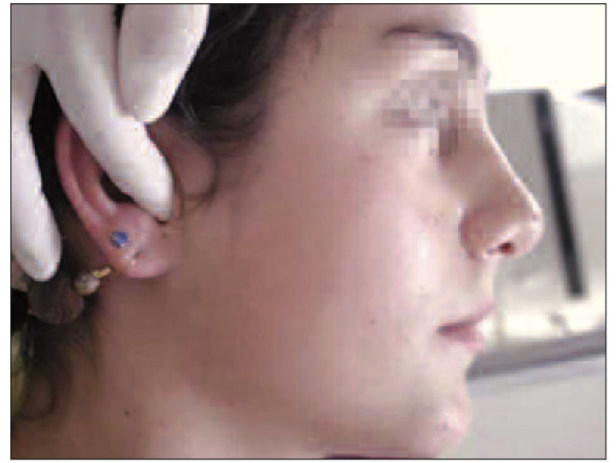

a

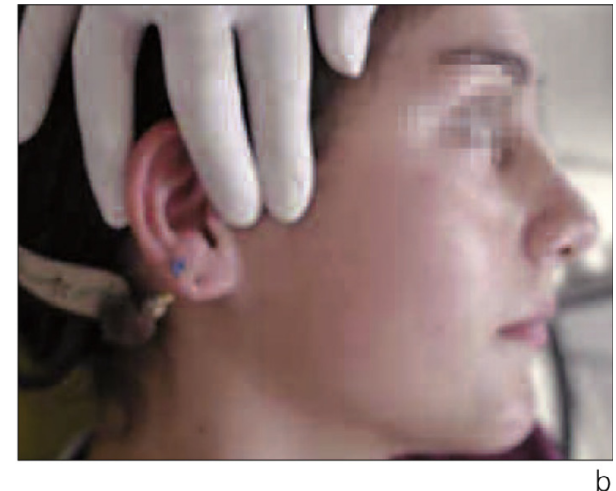

Figures $5 a$ and $5 b$

Palpation of posterior and external TMJ poles. chins and use their thumbs to resist this excursion with light pressure against the incisal edges of the mandibular incisors. They do the same as patients open and close, thus gently maintaining condyles and discs in place.

The index finger of the other hand is placed on the articular interline to perceive the pathway the condyle is taking on the articular surface of the temporal bone. With this manoeuvre examiners can discern the possible presence of obstacles within the joint to free translation of condyles that could cause disc dislocation or of excess condylar mobility as it passes over the articular eminence.

\section{- Articular compression (fig. 6)}

After conducting these tests, examiners use gentle pressure to assist upward and distal movement of the condyles. This manoeuver of posterior compression, unnoticed by patients with healthy TMJ, is painful when the joint is inflamed. This test gives examiners data for making a differential diagnosis between muscular and TMJ pain..
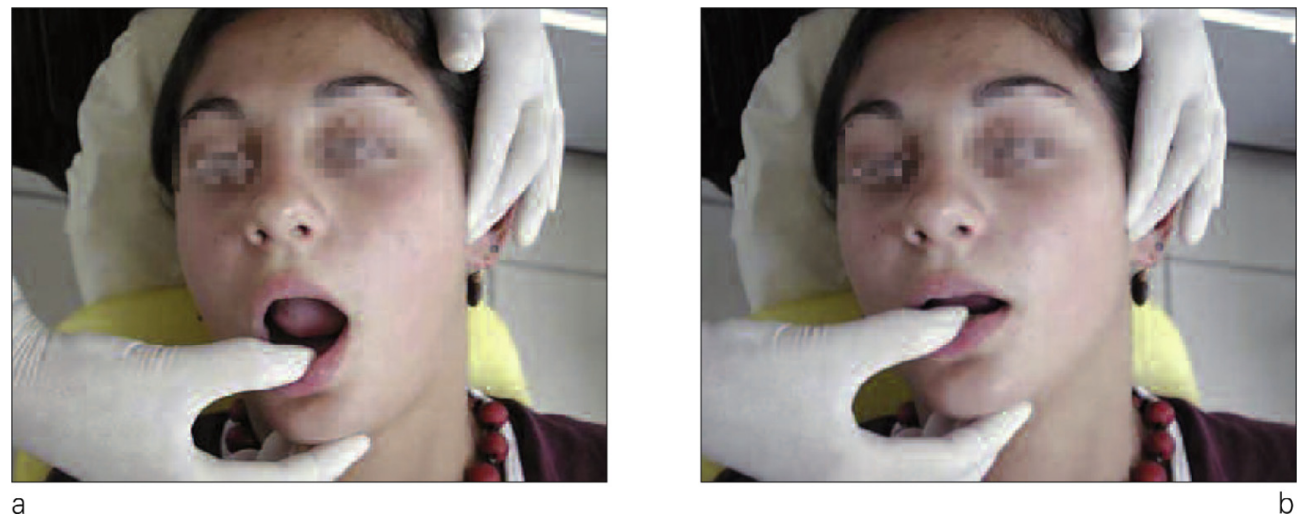

Figures $6 a$ and $6 b$

Guided TMJ movementd. Pressure on joint is final element of test. 


\section{7 - 3 - Examination of muscles by palpation}

- Practitioner palpates muscles of patient lying almost supine in a deeply lowered dental chair from behind, always symmetrically and always along the sense of the fibers from insertion to insertion.

\section{- Symmetry - Synchronism}

Practitioners note the symmetry, or lack of it, of the right and left homologous muscles in shape and volume at rest. Then they re-palpate any asymmetries or muscles not act-

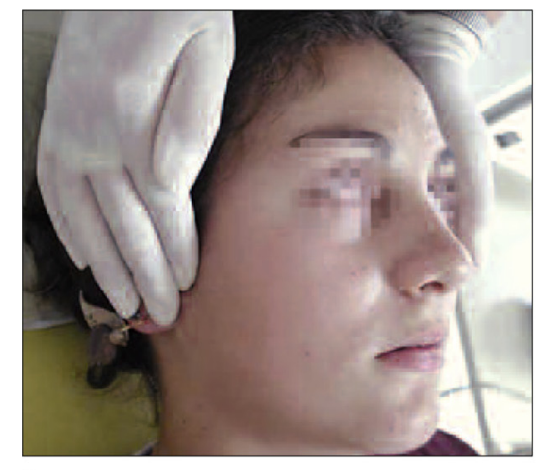

Figures $7 a$ and $7 b$

Palpation of the deep masseter (a) and the superficial masseter (b). ing in synchrony with fingers lying flat on the muscle masses during opening and closing and forward propulsion of the mandible.

Then, with the teeth in light contact, the practitioner observes the contraction and the relaxation of the muscles during clenching and relaxation of maximum intercuspidation.

- Sensitivity of masseter and temporal muscles (fig. 7 and 8 )

With fingers still lying flat, practitioners exert light pressure to slide the skin overlying the muscles back and forth a short distance. Then, with

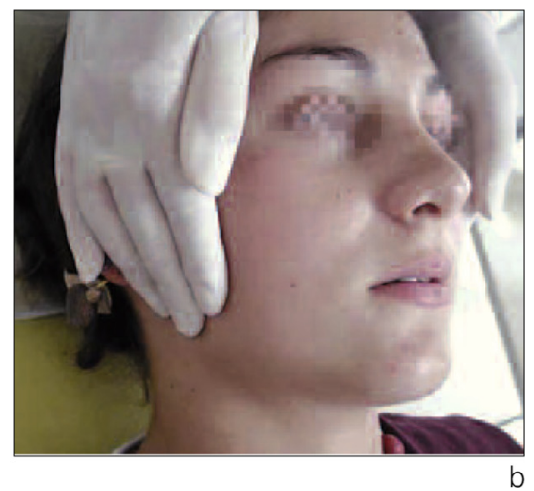


more pressure practitioners roll muscle masses searching for bands under tension. If one is found the practitioners pinch it as though it were a guitar string. With this manoeuver they can discern the origin of the pain patients had complained of.

\section{8 - TREATMENT PRINCIPLES}

\section{8 - 1 - Treatment objectives}

The 1996 American National Council of Health Conference 23 outlined the principle objectives of TMD treatment with these principles:

- ease pain

- improve function
- help patients to deal with future TMJ episodes in way that improves their quality of life ${ }^{12}$.

The response practitioners make to patients seeking help for TMJ pain should revolve around a number of axes including structural, functional, and behavioral, or bio-psychosocial. Treatments should be individualized

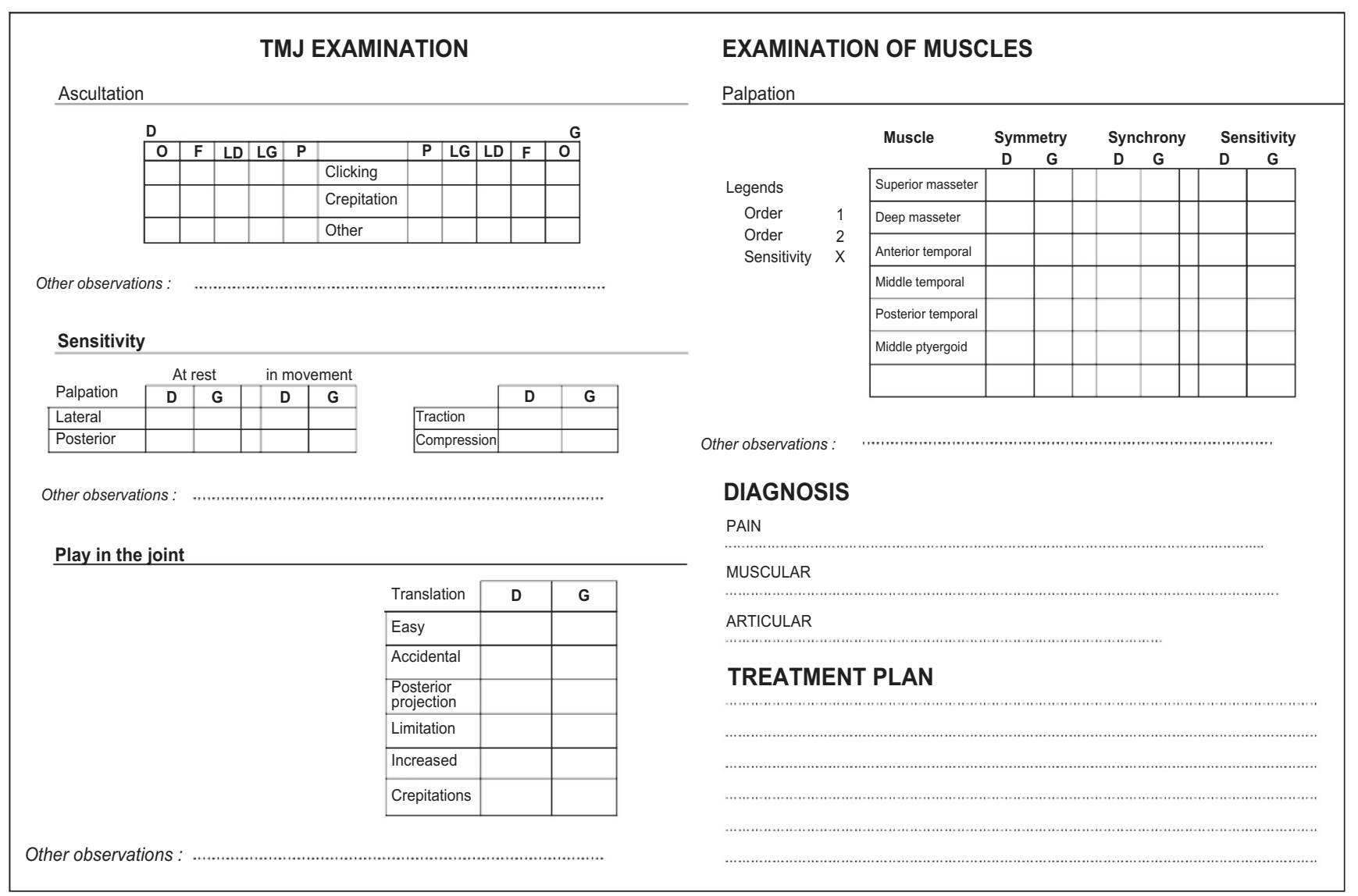

Figure 9

Record of the clinical examination. 
to suit the needs of each patient with regard to particular nature of their musculo-skeletal disorder and the psycho-social and behavioral problems they are confronting.

Treatment is designed to assist patients in understanding their disorders and how to deal with certain persistent etiological factors, primarily stress. Finally, practitioners give additional behavioral advice, perform any needed dental therapy, and, if necessary prescribe suitable medication.

\section{8 - 2 - Treatment modalities}

Success in TMD therapy depends, essentially, on motivation of patients and their active participation in the healing process. Treatment rarely exceeds six months; initial results should appear after the first three months. This treatment usually consists of a orthopedic splint accompanied by functional re-training that may consist of:

- ergotherapeutic recommendations;

- medication;

- kinesitherapy;

- bio-mechanical therapy;

- stress relief training.

\section{- Recommendations (ergotherapy)}

Practitioners provide patient with information that helps them minimize the extent and effort of mastication and change its pattern to avoid any unnecessary mandibular efforts like gum chewing, excessive yawning, even singing, and becoming aware of unhealthy parafunctions like clenching, bruxism, cheek chewing, chewing on objects like pipe stems and pencils. For some patients the embouchure of certain musical instruments can contribute to TMD.

\section{- Medication}

Practitioners may prescribe medications when pain is severe. These can be non-opiod analgesics like aspirin or acetaminophen, mild opiates like tramadol hydrochloride, anti-inflammatories like ibuprofen and diclofenac, or muscle relaxants like tetrazepam, all of which practitioners should utilize with a full understanding of the desired effects, as well as the possible undesirable side effects in order to obtain the best possible results.

\section{- Kinetherapy}

This consists of a relaxation exercise program of muscle stretching and reinforcement in opening, closing, and excursive movements.

\section{- Bio-mechanical therapy}

This is executed with hard plastic orthopedic splints made for mandible or maxilla that can be of two types.

\section{- Stabilization splints}

These can provide full or partial occlusal coverage depending on the needs of the case and are worn primarily at night. They are designed to essentially to stabilize and to re-distribute the inter-arch occlusal forces, to protect dental structures from abrasion and to decompress the TMJ but also to stimulate a contraction inhibition reflex by providing anterior guidance. 


\section{- Repositioning splints}

TMJ retention splints can be maxillary or mandibular plastic appliances that maintain the mandible in an asymptomatic position that impels it slightly forward enough to decompress the TMJ and allow it to recuperate. Lateral splints preserve this favorable position particularly during sleep.

\section{- Program for management of stress}

Proposed for patients having difficulty in dealing with TMD pain, stress relief should, if possible, be managed by a behavioral psychologist with the objective of attenuating or even removing that pain. Some cognitive behavioral techniques have been proposed to manage factors underlying chronic TMD pain such as malfunctional behavior and also to uncover and resolve phenomena of resistance and secondary gain.

\section{PAIN AND TEMPORO-MANDIBULAR DISORDERS: A CLINICAL CASE WITH COMMENTS WACYL MESNAY, ANNE CRUMBACH}

Miss L., an 18 year old high school student in good over-all health was referred to us by her general dentist for the pain in her TMJ that she had been suffering from for six months.

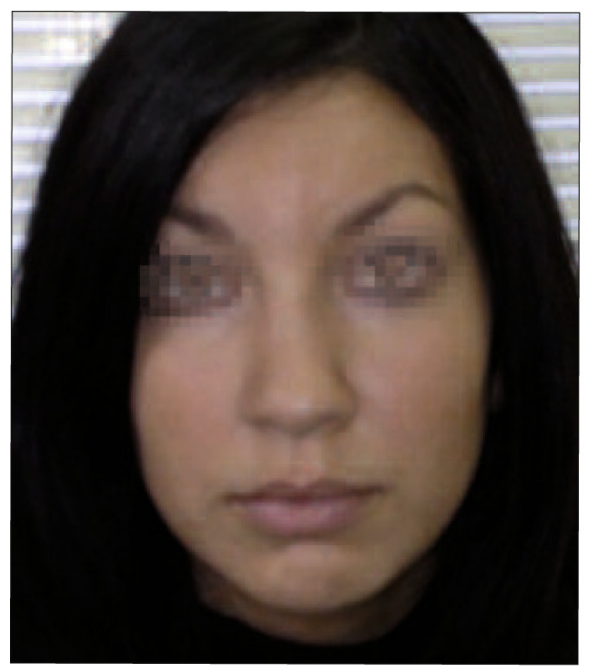

a

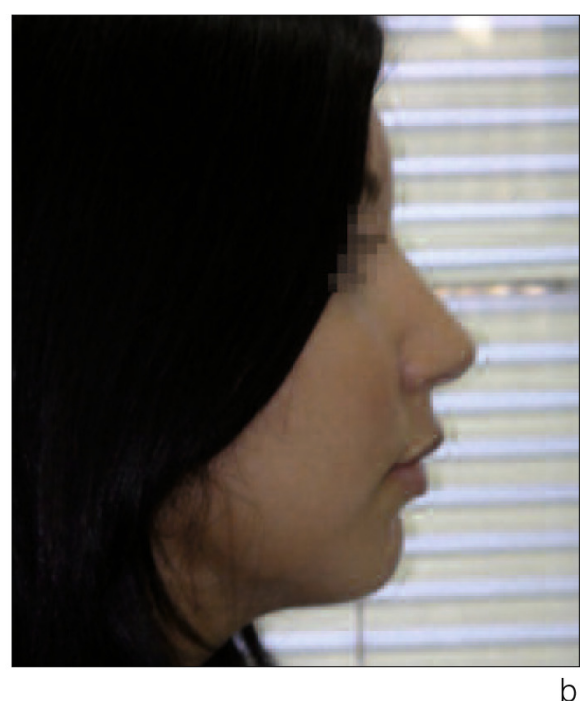

b

Figures 10a and 10b

Full face and profile view of Miss $L$. 


\section{9 - 1 - The initial interview}

This is the key element in the consultation in which we learn the patient's principal complaint, begin to understand her medical context, note the history of her previous treatments, and characterize her pain or handicap. It is the first step in formulating a diagnosis. In interviewing her, our goal was to determine the source of her TMD and to help her understand how it was related to stress.

\section{- Chief complaint or motive for consultation}

Miss L. consulted us on January 152010 because of acute pain in her right temporo-mandibular joint and a limitation in opening her mouth. She described the pain as sharp and causing a significant handicap in opening her jaw and in mastication.

The patient's desires were "not to have any more pain" and "to be able to open my mouth and eat normally." These 6 month long pains and joint noises described as "crackling" occurred when she opened her mouth. For the last month her pain had intensified and her mouth opening had become more and more limited.

She had no other pain, no disorders of sight, hearing, or posture. Nor, apart from the TMD, did she have any dental problems.

\section{- Pain}

By analyzing the characteristic of her symptom of pain, we are able to assess the role psycho-social elements play in causing it as we develop a differential diagnosis.

\section{- The site}

We note the location of pain on a schema that that describes its possible irradiations. The patient identified the pre-auricular region of the right TMJ as the principal site.

\section{- The date and the circumstances of its first appearance.}

The pain began in March 2009, toward the end of her orthodontic treatment. Since then it has grown worse.

\section{- The intensity}

Intensity is measured with the $\mathrm{Vi}$ sual analog scale, which is a $10 \mathrm{~cm}$ long horizontal line running from 0 , the absence of pain, to 10 , the most intense pain. The patient points to a point on the line in response to the question, "On a scale of 1 to 10 , how intense is your pain?" In her initial consultation Miss L. had located the intensity of her pain as between 7 and 8.

\section{- Frequency}

She said she felt the pain every day and said it appeared during function, when she opened her mouth and in mastication.

\section{- "Quality" of pain}

Patients are asked to describe the nature of their pain. Miss said that her discomfort was, disagreeable, crushing, ringing, lancing, annoying, and tiring.

The terms "annoying" and "tiring" are affective expressions and are related to the patient's emotional state. 
At this stage of the interview we determined that Miss L.'s problem was:

\section{- an organic pain:}

a category that indicates that a pain is intimately associated with the lesion that caused it because it appeared during function, was variable in the times it occurred and how long it lasted, was little, or scarcely, noticeable to the people she encountered, and, therefore, did not affect her social milieu. But it was clearly.

- a "pain issue", associated with psychosocial and affect factors that maintained and aggravated the sensation of pain. The intensity of this kind of discomfort can often be elevated to a point where patients fear it is permanent and, after about 3 months, is no longer related to function. This is when the pain begins to perturb the social and professional lives of afflicted individuals. The problem becomes a painful process that can appear in the morning or later in the day.

And it was precisely this type of emotional torment that was exacerbating Miss L.'s level of distress.

\section{- The differential diagnosis}

The limitation of mouth opening and the characteristics of the pain, its nature, as well as its appearing during function all indicated to us that Miss L.'s problem originated in the masticatory system and was not reflected from a neighboring region, sinusitis, a temporal arteritis, nor was it neurovascular, neuropathic, or a problem from an infected tooth. The clinical examination that we conducted immediately after the interview allowed us to assess the existence of a sensorial component.

\section{- Search for traumatic factors}

Important elements to consider include:

- a blow to the chin suffered at some time before onset of symptoms can be the possible underlying factor in TMD but when the possible trauma occurred a long time before the current malady, as was the case with Miss L., it is difficult to document cause and effect.

- the orthodontic treatment that Miss L. had completed 6 months previously can also be ruled out

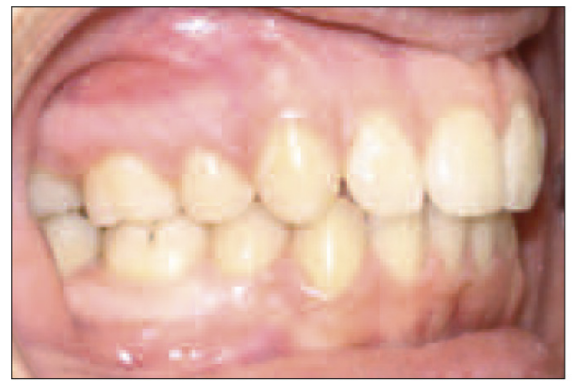

a

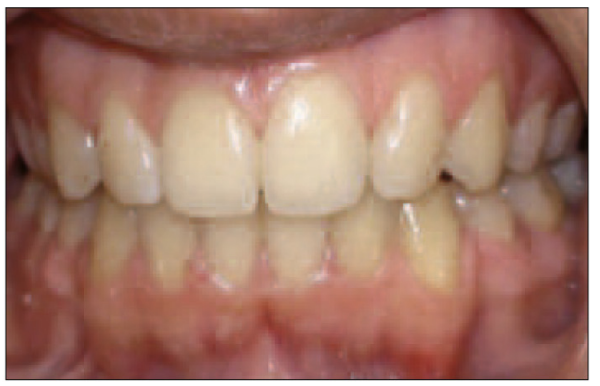

b

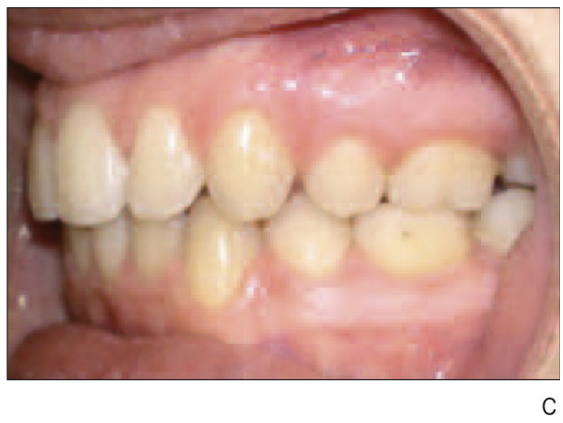

Figures 11a to $11 \mathrm{c}$ Intraoral photographs of Miss L. 
because no clinical evidence-based study has ever been able to prove that there is any connection between TMD and orthodontic treatment. Furthermore, other studies of temporo-mandibular disorders have demonstrated that adolescents suffer from them at a high rate. So it is by no means rare to see young patients have their appliances removed and soon after develop TMD. It is likely that when wearing appliances patients stop clenching their teeth and resume the practice when orthodontic force is no longer being applied to their dentitions.

And, in fact, Miss L. told us she was a victim of bruxism. She was conscious of clenching her teeth at night.

\section{- Searching for psychosocial factors}

Our patient, Miss L., an 18-year-old high school senior who lives with her parents, her brother, and her sister, has no problems dealing with her family members. But she did discontinue her participation in sports

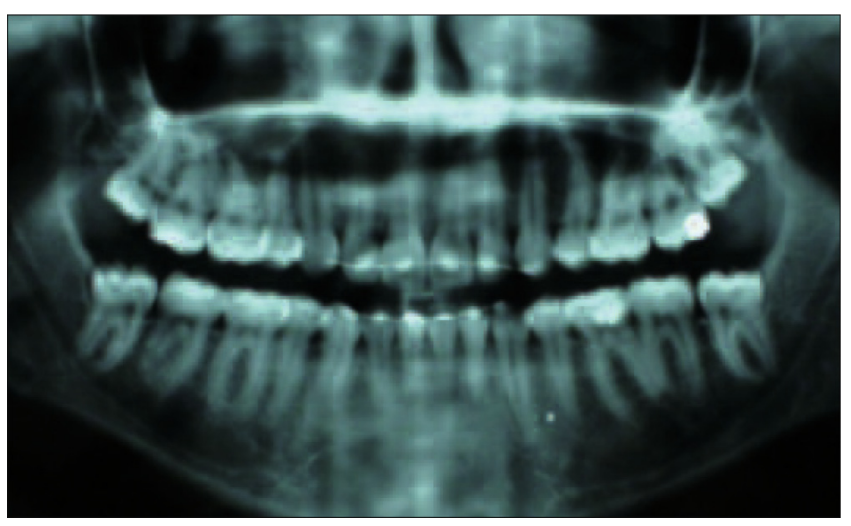

Figures 12

Panoramic radiogram o Miss L.'s dentition. recently because of the stress the preparation for her upcoming baccalaureate examination was exerting on her.

This type of emotional distress is a recognized factor that maintains TMD. The vegetative hyperactivity that follows it contributes to muscular tension as well as to bruxism. Problems appear after repeated episodes of micro trauma that overload the adaptive capacity of the temporo-mandibular joint.

\section{9 - 2 The clinical examination}

Examiners use inspection, palpation, and auscultation to evaluate the status of the functioning of the temporo-mandibular joint, the oro-facial muscles, and the muscles of mastication in order to derive an under-

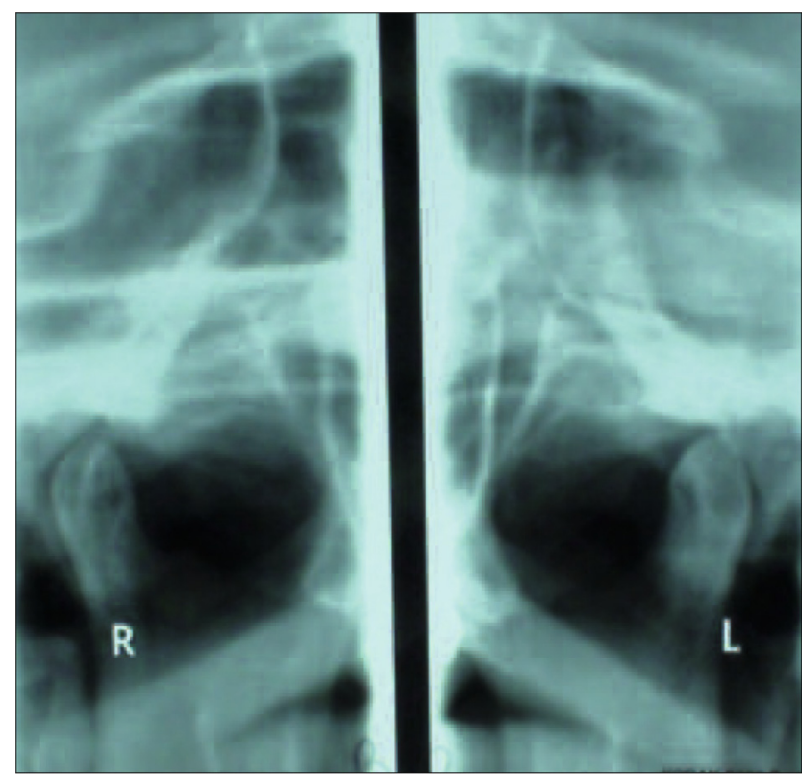

Figure 13

Radiographs of Miss L.'s TMJs with mouth open. Note the limitation of translation of the right condyle owing to disc displacement. 
standing of the problem and to find the origin of the pain. Making a positive diagnosis is an indispensable prerequisite to the implementation of any treatment plan.

\section{- The functional assessment}

Miss L.'s limited mouth opening of $30 \mathrm{~mm}$ was markedly lower than the normal value range of 35 to $40 \mathrm{~mm}$. It was also painful and deviated to the right. Her other mandibular movements were reduced, with deviated propulsion only $6 \mathrm{~mm}$, right excursion $8 \mathrm{~mm}$, and, especially left excursion of only $5 \mathrm{~mm}$. All were painful.

- A limitation of propulsive movement in the TMJ is a sign of the presence of an intra-articular obstruction. Miss L.'s right TMJ showed impeded movement in our examination.

\section{- Examining the TMJ}

\section{- Auscultation}

Our exam revealed no noises in movements of Miss L.'s temporomandibular joints.

\section{- Sensitivity}

Miss L.'s right TMJ was sensitive to lateral and posterior palpation at rest and in opening. She also felt pain on its being compressed, which is a sign of disc inflammation.

\section{- Play in the TMJ}

In our examination of Miss L.'s right temporo-mandibular joint we observed a limitation of translation of the right condyle, which confirmed our diagnosis of right TMJ disc displacement.

\section{- Examination of muscles}

\section{- Sensitivity}

Examiners palpate the deep elevator muscles in a search for pain, muscular stiffness, and painfully stiff muscle bands. On palpation of the deep right masseter, Miss L. felt pain.

\section{- Synchronism and symmetry}

With bilateral superficial palpation we were able to discern a lack of synchrony in the contraction of right and left symmetrical muscles and a differential in their volumes.

Furthermore our exam revealed an asynchrony of the deep masseter muscles in closing.

\section{9 - 3 - The diagnosis}

A diagnosis of TMD is based on a fault in three elements, pain, articulation, and muscles.

\section{- Diagnosis of pain:}

Miss L. presented with:

- a mild level of pain, which had developed in a context of academic stress, of which she was clearly aware. Accordingly the prognosis is favorable because the triggering problem is identified and the patient can find a solution to it by modifying her behavior.

- Miss L.'s acute organic pains are associated with a non-recapturable displaced disc associated with capsulitis and a spasm of the right deep masseter. 


\section{- TMJ diagnosis}

\section{- A capsulitis}

The pain Miss L. felt on palpation and compression of the right TMJ is a sign of inflammation of an articular capsule.

\section{- A non-recapturable displaced disc:}

We detected the disc luxation by noting the limited and deviated opening trajectory in mandibular propulsion.

And we confirmed this diagnosis in our TMJ exam when we detected the presence of an obstacle to translation of the head of the right mandibular condyle.

During the course of an acute nonreducible luxation, the disc is displaced or deformed in advance of the head of the condyle, which can no longer recapture it on opening. Miss L.'s right TMJ made no noises. The pain and the limited opening were her principal symptoms. In fact, the movement of her right condyle as it passes into the stage of the disc being non-capturable with its anterior position constituting a pathological obstacle. In these cases a lesion of the posterior ligament is frequently associated with the displaced disc, provoking intra-articular inflammation or capsulitis.

\section{- Diagnosis of muscles}

\section{A splinting reflex (myospasm)}

The splinting reflex, or myospasm, of Miss L.'s deep right masseter was a reaction of muscle rigidity secondary to the articular inflammation. It is the body's attempt to protect the TMJ by immobilizing muscles that activate it but the patient senses it by feeling muscular pain and an inability to open the mouth to a normal extent.

\section{- Etio-pathogenic hypotheses}

The TMJ must have suffered a traumatic shock to the mandible at some time before onset of symptoms, as was previously explained above. And to this insult an episode of recurrence of bruxism associated with, in Miss L.'s case, academic stress and amplified by removal of orthodontic appliances may have been triggering factors.

During disc displacement, elongation of a ligament beyond a normal limit can provoke a posterior ligament lesion causing inflammation of the TMJ.

The clenching reflex, which is secondary to this capsulitis, locks articular movement giving the TMJ a period of off time in which to heal.

\section{9 - 4 - Treatment}

The modern approach to TMD treatment consists of veritable orthopedic management of the affected joint. Initial therapy is to treat the pain and the handicap so that function can be restored and relapse prevented.

Treatment strategy aims at treating the inflammation with medication and immobilizing the joint. Because total immobilization of the TMJ is not possible, dentists help patients to rest the ailing joint by fabricating an orthesis of TMJ Retention to wear at night and providing them with ergotherapy to ameliorate their daytime oral behavior. 
In the first therapy appointment, dentists prepare a partial NTI orthesis that they fully construct, adjust, and deliver at the chair (fig. 14). They ask patients to wear it at night and occasionally during the day. As the initial symptoms begin to disappear, dentists then give patients functional reeducation lessons designed to help them recover normal masticatory capabilities.

\section{- Emergency treatment for TMD pain}

When we first saw Miss L. on January 115, 2010, she evaluated her pain on the Visual Analog Scale as 7 out 10 and her handicap as 10 out of 10. She needed immediate help.

After formulating our diagnosis, to soothe her pain swiftly we prescribed medication consisting of analgesic and anti-inflammatory drugs, one $75 \mathrm{mg}$ pill of Diclofenac in the morning and one at night for 7 days.

We immediately constructed and delivered a Nociceptive Trigeminal Device, NTI, to reduce the clenching reflex. As we explained, the NTI has the great advantage of its immediate construction at the chair. It gave Miss L. relief that would provide her with the protection she needed until we could make a more adaptive orthesis for her.

During her first visit we completed the initial implementation of our treatment plan by showing her how to perform stretching exercises of opening, closing, and lateral mandibular movements. We then took supplementary panoramic and TMJ X-rays.

We then took impressions for study models that could be used for fabrication of an articular retention device for delivery on her next appointment.

\section{- Treatment of TMD and its stabilization}

We employ a variety of modalities to treat $T M D$, including:

- ergotherapy that begins by making patients aware of parafunctions like nighttime bruxism or daytime tooth clenching and then gives them behavioral counseling on how to keep the mandible in good health by not chewing gum excessively or munching on hard food particles. They are also shown how to use moist heat for muscle pain or ice for inflammation of the TMJ.

We believe that the indications for use of the Articular Retaining Orthesis (fig. 15) are multiple, to decompress or immobilize the TMJ and, in doing so, reduce the activity of the muscles of mastication.

The therapeutic objective of this orthesis is to liberate the TMJ from posterior constraints and allow it to recuperate. The forward position of the mandible that the device encourages also modifies muscular activity.

Patients should wear the Articular Retaining Orthesis 8 to 10 hours per day, principally at night. It is a transition appliance, worn for no longer than 6 months. We do not use it to establish a new position for the mandible to occupy but basically to temporarily disengage the temporomandibular joint from its habitual constraints. 


\section{- Stages of treatment}

After patients have received their ortheses and learn how to perform their functional re-education exercises they return for regular follow-up visits so that we can observe their progress in resolving their temporomandibular disorder.

At every appointment we check progress in pain relief and correction of their handicap on the Visual Analog Scale and assess amplitude of mandibular movements.

We repeat and reinforce oral behavioral counseling and try to determine how faithfully patients are wearing appliance and performing the exercises we prescribed for them.

On March $3^{\text {rd }} 2010$ the patient described her pain level as 2 out of 10 against the 7 out of 10 she was burdened with in her pre-therapy crises. She can now perform all mandibular movements without pain and crisis develop only after prolonged periods of mastication. Her mouth opening amplitude was $40 \mathrm{~mm}$, a gain of $10 \mathrm{~mm}$. Her right lateral excursion was $10 \mathrm{~mm}$, a gain of $2 \mathrm{~mm}$, and her left lateral excursion was $9 \mathrm{~mm}$, a gain of $4 \mathrm{~mm}$. She had attained

\section{0 - ANNEX}

\section{Current recommendations for TMD therapy}

\section{- Capsulitis}

TMJ pain on palpation and compression are signs of capsulitis, or inflammation of the articular capsule. these improvements by wearing the NTI appliance faithfully, taking her medication regularly, and by performing her stretching exercises as prescribed.

On April $4^{\text {th }}$ 2010, 3 weeks after receiving her Articular Retaining Orthesis, which she regularly wore 4 to 5 nights per week, all pain had disappeared and again she could eat without discomfort. And her mandibular movements had returned to normal, opening of $45 \mathrm{~mm}$, right and left excursions of $12 \mathrm{~mm}$, and propulsive of $11 \mathrm{~mm}$.

We advised the patient to continue her stretching exercises and to return in 6 weeks for a check-up.

On June $18^{\text {th }}$ we determined that Miss L. was wearing her Articular Retaining Orthesis regularly and exercising at an average rate. She had felt no pain since the previous visit. The amplitude of her opening and excursive movements remained normal.

We then detached the lower portion of the Articular Retaining Orthesis transforming it into a maxillary stabilizing orthesis. We advised her to continue to wear it during sleeping hours for an additional 3 months.
Current therapeutic approach:

- medication for relief of pain and inflammation,

- functional re-education,

- stabilization or retention orthesis for the TMJ. 


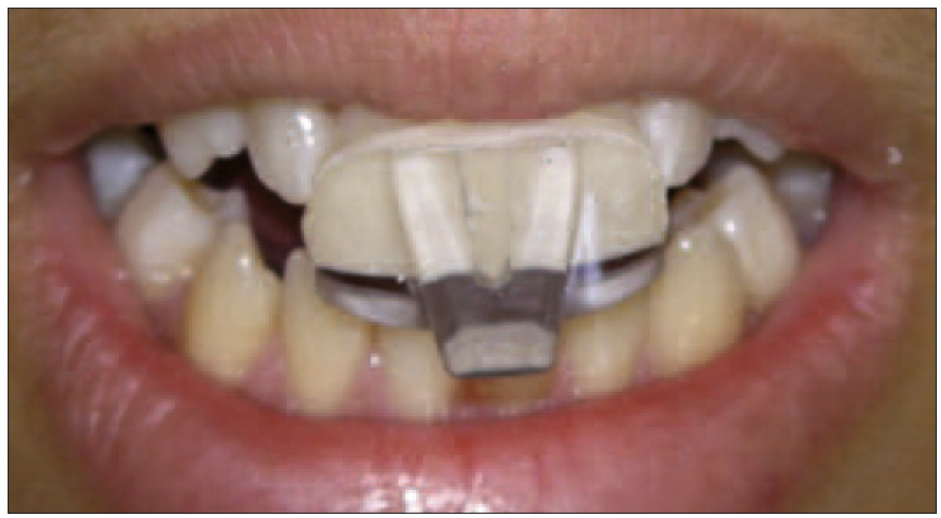

Figure 14

An NTI device in the mouth. Its action, like that of a Lucia Jig, is to inhibit contraction of the mandibular elevator muscles. Its great advantage is that dentists can construct it at the chair and deliver it to the patient immediately, in a relatively high state of finishing.

\section{- The splinting reflex}

Miss L.'s splinting reflex, or myospasm, of the right deep masseter was a muscle rigidity reflex secondary to inflammation of the right TMJ disc. It is the body's attempt to protect the injured TMJ by blocking its movement. Patients experience it essentially through the muscle pain and the limitation of opening that it provokes.

Current therapeutic approach:

- Placement of a total or partial stabilization device for neuromuscular reconditioning.

- Analgesic and muscle relaxing medication.

- Functional re-education with muscular stretching and re-conditioning exercises.

\section{- Non-recapturable disc displacement}

Examiners can discern the presence of disc displacement when they perceive patients have a limited and deviated trajectory in performing

\section{propulsion excursion of the mandible.}

For Miss L. we confirmed that diagnosis in examining her temporomandibular joints. We detected an obstacle to the translation of the head of her right mandibular condyle.

In a non-recapturable luxation, the disc is displaced, or deformed, in advance of the condyle, where it cannot be re-captured on mouth opening. The resultant pain and limitation of the mandible's opening become the principal symptoms. In effect, the non-recapturable advanced position of the disc greatly diminishes the biomechanical capabilities of the affected condylar head. Worsening matters, the development of a lesion on the posterior ligament associated with disc displacement often provokes intra-articular inflammation, or capsulitis, as it did with Miss L. 


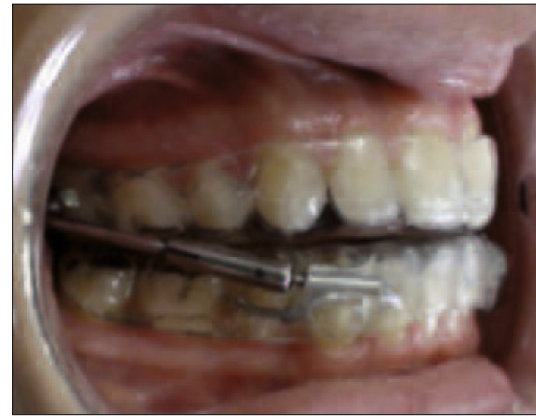

a

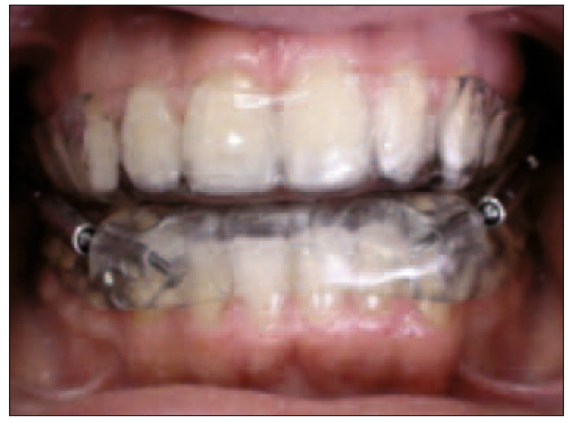

b

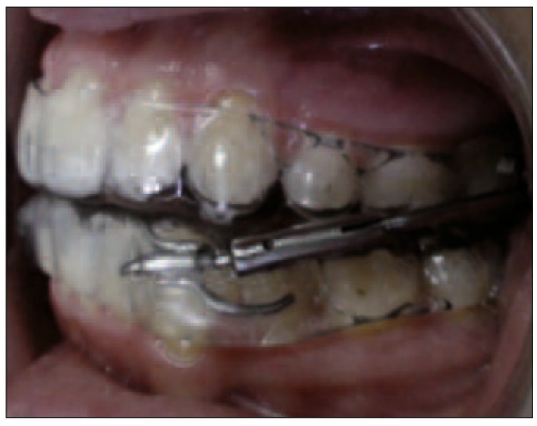

Figures 15 a to $15 \mathrm{c}$

The articular retention orthesis is composed of two splints, a mandibular and a maxillary, joined together with lateral threaded tube extensions. It acts as an immobilizer and a veritable decompressor of the TMJs. The maxillary component is constructed in accordance with the criteria for an occlusal liberation orthesis. The dentist, at the appropriate time, can detach the mandibular component to transform the maxillary sector into an orthesis for the second phase of treatment.

Current therapeutic approach:

- Placement of an articular retention orthesis to help re-establish articular function.

- Functional re-education: guided mandibular mobilization exercises.

The Articular Retention Orthesis consists of a mandibular and a maxillary splint. The maxillary component is constructed in accordance with the criteria for an "occlusal liberation" orthesis. The mandibular component is a simple occlusal coverage splint.

Its two lateral extensions keep the mandible in a slight, 2 to $3 \mathrm{~mm}$, ad- vanced position, liberated from posterior constraints. Dentists can regulate the lateral wings to allow the mandible to return slowly to its normal position, a process that is completed when all symptoms have disappeared. The lateral wings are detachable and the lower portion of the device can be ground away transforming the device into a classical "liberation" orthesis to be employed in the next stage of treatment.

This temporary therapeutic immobilization offers the TMJs veritable decompression and the rest period they need for recuperation.

\section{REFERENCES}

1. Aghabeigi B, Feinmann C, Glover V, Goodwin B, Hannah P, Harris M, Sandler M, Wasil $M$, Tyramine conjugation deficit in patients with chronic idiopathic temporomandibular joint and orofacial pain. Pain 1993;54:159-63.

2. American Psychiatric Association. Diagnostic and Statistical Manual of Mental Disorders DSMIV-TR (Text Revision). In: American Psychiatric Association (ed). 4th ed. Washington (DC): American Psychiatric Publishing, 2000:498-503. 
3. Amtz $A$, Dreesen $L$, de Jong $P$. The influence of anxiety on pain: attentional and attributional mediators. Pain 1994;56:307-14.

4. Braun BL, DiGiovanna A, Schiffman E, Bonnema J, Fricton J. A crosssectional study of temporomandibular joint dysfunction in post-cervical trauma patients. J Craniomandib Disord Fac Oral Pain 1992;6:24-31.

5. Bridges RN, Goldberg DP. Somatic Presentation of DSM-III psychiatric disorders in primary care. Psychosom Res 1985; 29:5639. [41.] Lipowske ZJ. Somatization: the concept and its clinical application. Am J Psychiatry 1988;145:1358-68.

6. Carlson CR, Okeson JP, Falace DA, Nitz AJ, Curran SL, Anderson D. Comparison of pychologic and physiologic functioning between patients with masticatory muscle pain and matched controls. J Orofac Pain 1993;7:15-22.

7. Carlsson GE, Magnusson T. Management of Temporomandibular Disorders in the General Dental Practice. $1^{\text {st }}$ ed. Chicago: Quintessence Books, 1999.

8. Drangsholt M, LeResche L. Temporomandibular Disorder Pain. In: Crombie IK, Croft PR, Linton SJ, LeResche L, Von Korf M (eds). Epidemiology of Pain. $1^{\text {st }}$ ed. Seattle: IASP Press, 2000:20333.

9. Dworkin SF, LeResche L. Research diagnostic criteria for temporomandibular disorders. <http://rdc-tmdinternational.org>. Accessed mars, 4. 2004.

10. Dworkin SF, LeResche L. Research diagnostic criteria for temporomandibular disorders: Review, criteria, examinations and specifications, critique. J Craniomandib Disord. 1992;6(4):301-55.

11. Goulet JP, Lavigne GJ, Lund JP. Jaw pain prevalence among French-speaking Canadians in Quebec and related symptoms of temporomandibular disorders. J Dent Res 1995;74:1738-44.

12. Goulet JP, Lavigne GJ. Mieux comprendre et traiter les problèmes temporomandibulaires. Le Médecin du Québec 2004;39(7):37-45.

13. Harkins SJ, Marteney JL. Extrinsic trauma: a significant precipitating factor in temporomandibular dysfunction. J Prosthet Dent 1985;54:271-2.

14. Hubbard DR, Berkoff GM. Myofascial trigger points show spontaneous needle EMG activity. Spine 1993;18:1803-7.

15. Koidis PT, Zarifi A, Grigoriadou E, Garefis P. Effect of age and sex on craniomandibular disorders. J Prosthet Dent 1993; 69:93-101.

16. Kononen M, Nystrorn M. A longitudinal study of craniomandibular disorders in Finnish adolescents. J Orofac Pain 1993; 7:32936.

17. Lund JP, Donga R, Widmer CG, Stohler CS. The pain-adaptation model: a discussion of the relationship between chronic musculoskeletal pain and motor activity. Can J Physiol Pharmacol 1991;69:683-94.

18. Lund JP, Widmer CG. Evaluation of the use of surface electromyography in the diagnosis, documentation, and treatment of dental patients. J Craniomandib Disord Fac Oral Pain 1989;3:125-37.

19. Mesnay W. Troubles temporo-mandibulaires: Intérêt d'une approche thérapeutique cognitive et comportementale. Mémoire de Diplôme Universitaire en thérapies comportementales et cognitives [dissertation]. Paris : Université René Descartes, 1998.

20. Mense S. Nociception from skeletal muscle in relation to clinical muscle pain. Pain 1993;54:241-89.

21. Merskey H, Bogduk N, eds. Classification of Chronic Pain. In: IASP Task Force on Taxonomy. $2^{\text {nd }}$ ed. Seattle, Wash: IASP Press 1994:209-14.

22. Morrison J, Herbstein J. Secondary affective disorder in women with somatization disorder. Compr Psychiatry 1988;29:433-40.

23. National Institutes of Health. Management of Temporomandibular Disorders <http://consensus.nih. gov/ta/018/018_statement.htm>. Accessed 03/20. National Institutes of Health Technology Assessment Conference Statement, 1996. 
24. Ohrbach R, Sherman J. Temporomandibular Disorders. In: Dworkin RH, Breitbart WS (eds). Psycho-social Apects of Pain: A Handbook for Helth Care Providers. $1^{\text {st }}$ ed. Seattle: IASP Press, 2004:405-25.

25. Okeson JP (ed). Orofacial Pain: Guidelines for Assessment, Diagnosis, and Management. $1^{\text {st }}$ ed. Chicago: Quintessence Books, 1996.

26. Perry F, Heller PH, Kamiya J, Levine JD. Altered autonomic function in patients with arthritis or with chronic myofascial pain. Pain 1989;39:77-84.

27. Seligman DA, Pullinger AG. The role of intercuspal occlusal relationships in temporomandibular disorders: a review. J Craniomandib Disord Fac Oral Pain 1991;5(2):96-106.

28. Skolnick J, Iranpour B, Westesson PL, Adair S. Prepubertal trauma and mandibular asymmetry in orthognathic surgery and orthodontic paients. Am J Orthod Dentofac Orthop 1994;105:73-7.

29. Turk DC, Rudy TE. The robustness of an empirically derived taxonomy of chronic pain patients. Pain 1990;43:27-35.

30. Von Korff M, Dworkin SF, LeResche L, Kruger A. An epidemiologic comparison of pain complaints. Pain 1988; 32:173-83.

31. Wanman A. Longitudinal course of symptoms of craniomandibular disorders in men and women. A 10-year follow-up study of an epidemiologic sample. Acta Odontol Scand 1996;54:33742.

32. Wright EF. Manual of Temporomandibular Disorders. Ames, IA: Blackwell Munksgaard, 2005. 